Ana Maria Caldeira Oliveira ${ }^{1}$

Sueli Gandolfi Dallari ${ }^{1}$

\title{
Representações sociais dos conselheiros municipais de saúde sobre a vigilância sanitária
}

\author{
Social representations of municipal health counselors \\ on health surveillance
}

Sueli Gandolfi Dallari

${ }^{1}$ Faculdade de Saúde Pública, Universidade de São Paulo. Av. Dr. Arnaldo 715, Cerqueira Cesar. 01246904 São Paulo SP Brasil. amcoliveira@usp.br

\begin{abstract}
The objective of this study is to describe and analyze the social representations of the Health Counselors of the city of Belo Horizonte regarding their experiences with health surveillance. The research used the interview technique based on a semi-structured script. The data obtained were analyzed using the Collective Subject Discourse technique. It was found that the existing gap between health surveillance and the $\mathrm{Mu}$ nicipal Health Council is offset by the broad spectrum of "hands-on" experience acquired by the counselors. This experience assumes greater significance in terms of practical knowledge, directly influencing the thinking and know-how of these individuals on the topic. In practice, proof of the social appropriation of the importance of health surveillance as health action qualifies as an effective model of health care. It effectively influences the determinants and conditioning factors of the health/sickness process, while simultaneously promoting educational initiatives that contribute to raising health awareness.
\end{abstract}

Key words Social representations, Health surveillance, Health counselors
Resumo O objetivo do estudo é descrever e analisar as representações sociais dos Conselheiros de Saúde de Belo Horizonte sobre suas experiências com a vigilância sanitária. A pesquisa utilizou a técnica de entrevista baseada em roteiro semiestruturado. Os dados obtidos foram analisados pela técnica do Discurso do Sujeito Coletivo. Verificouse que o distanciamento existente entre a vigilância sanitária e o Conselho Municipal de Saúde é compensado pela riqueza das experiências "vividas" dos conselheiros. Essas experiências foram ressignificadas em saber prático, influenciando diretamente o pensamento e o conhecimento desses sujeitos sobre o tema. Por fim, a comprovação da apropriação social sobre a importância da vigilância sanitária como ação de saúde a qualifica como eficaz modelo de atenção à saúde, intervindo sobre os fatores determinantes e condicionantes do processo saúde doença, ao mesmo tempo em que promove ações educativas que contribuem para elevar a consciência sanitária.

Palavras-chave Representações sociais, Vigilância sanitária, Conselheiros de saúde 


\section{Introdução}

A Constituição Federal de $1988^{1}$ assegurou o direito universal à saúde. A saúde reconhecida $\mathrm{e}$ proclamada como direito fundamental da pessoa humana e necessidade essencial de todos os indivíduos $^{2}$. Nesse contexto, a compreensão sobre o conceito de saúde foi alterada, passando a ser entendida como resultante das condições de vida e das formas de organização da produção. Como consequência, nesses 25 anos de construção do Sistema Único de Saúde (SUS), os questionamentos sobre a ineficácia do modelo de atenção médico hegemônico levaram à busca de novas formas de pensar e agir em saúde, favorecendo a adoção de modelos que privilegiam a intervenção sobre os fatores determinantes e condicionantes do processo saúde doença ${ }^{3}$.

Com efeito, esta Constituição ${ }^{1}$ reconheceu a saúde como direito fundamental do ser humano, vinculando-a às políticas sociais e econômicas, com o objetivo de redução do risco de agravos, bem como a garantia de acesso universal e igualitário às ações e serviços de saúde, destinados não só à sua recuperação, mas também à sua proteção e promoção ${ }^{1}$. Segundo Lucchese ${ }^{4}$, uma das principais funções do Estado democrático moderno é a de proteger e promover a saúde e o bem-estar dos cidadãos. Desse modo, cabe ao Estado zelar pelos interesses coletivos, intervindo nas atividades de particulares, disciplinando-as, quando essas implicarem em risco para a Saúde Pública.

Dallari ${ }^{5}$ observa que tanto na Constituição de 1988, como na Lei Orgânica da Saúde, as atividades destinadas à proteção da saúde são bastante enfatizadas, aparecendo tanto subsumidas na expressão "vigilância sanitária", quanto de forma expressa nas ações de controle e fiscalização de procedimentos, produtos e substâncias de interesse para a saúde. A vigilância sanitária teve definido o seu caráter preventivo e de intervenção nos problemas sanitários na Lei Orgânica da Saúde, a Lei Federal no 8.080/906 ${ }^{6}$. Dispõe o $\$ 1^{\circ}$ do art. $6^{\circ}$ :

Entende-se por vigilância sanitária um conjunto de ações capaz de eliminar, diminuir ou prevenir riscos à saúde e de intervir nos problemas sanitários decorrentes do meio ambiente, da produção e circulação de bens e da prestação de serviços de interesse da saúde, abrangendo: I- o controle de bens de consumo que, direta ou indiretamente, se relacionem com a saúde, compreendidas todas as etapas e processos, da produção ao consumo; e II- $o$ controle da prestação de serviços que se relacionam direta ou indiretamente com a saúde.
Nesse sentido, o Plano Diretor de Vigilância Sanitária (PDVISA) ${ }^{7}$ da Agência Nacional de Vigilância Sanitária (Anvisa), considerando as prerrogativas legais de intervir em espaços onde atuam forças de mercado e interesses econômicos, e cujos resultados influenciam as condições de vida e de saúde da população, estabeleceu como uma de suas diretrizes a "Promoção de ações que contribuam para elevar a consciência sanitária da sociedade, na percepção do risco sanitário e na compreensão do funcionamento do Sistema Nacional de Vigilância Sanitária, incluindo os aspectos da universalidade, do acesso, da democratização da informação, da comunicação e da transparência"'.

\section{Representações Sociais}

A representação social é um conceito da sociologia de Durkheim que é teorizado na psicologia social desenvolvida por Moscovici ${ }^{8}$ sob a denominação de Teoria das Representações Sociais (TRS). Para Arruda ${ }^{9}$, a TRS operacionaliza um conceito para se trabalhar com o pensamento social, abordando sua dinâmica e sua diversidade. Parte da premissa de que existem formas diferentes de conhecer e de se comunicar, guiadas por objetivos diferentes, e define duas delas: a consensual e a científica. "O universo consensual seria aquele que se constitui na conversação informal, na vida cotidiana, enquanto o universo reificado se cristaliza no espaço científico, com seus cânones de linguagem e sua hierarquia interna"'.

Segundo a autora, apesar de terem propósitos diferentes ambas são eficazes e indispensáveis à vida humana. No universo consensual aparentemente não há limites, podendo todas as partes se manifestarem, enquanto que no universo reificado só podem falar os especialistas. As representações sociais constroem-se mais frequentemente na esfera consensual, embora as duas esferas não sejam totalmente separadas.

Moscovici, citado por Spink ${ }^{10}$, reconhece que ao enfatizar o poder de criação das representações sociais, observando sua dupla face de estruturas estruturadas e estruturas estruturantes, inscreve sua abordagem entre as perspectivas construtivistas. Desse modo, a psicologia social aborda as representações sociais no âmbito da relação indivíduo-sociedade, com interesse pela cognição. Por um lado ela reflete sobre como os indivíduos, os grupos e os sujeitos sociais constroem seu conhecimento a partir da sua inscrição social e cultural, e, por outro, como a sociedade 
se dá a conhecer e constrói esse conhecimento com os indivíduos?.

Dessa forma, o que está em pauta é o conhecimento do homem comum. É o desvelamento do conjunto de significados que sustentam o cotidiano e sem a qual nenhuma sociedade pode existir $^{10}$. Nessa perspectiva, o objeto de estudo deste trabalho são as representações sociais dos Conselheiros de Saúde de Belo Horizonte sobre suas experiências com o campo da Vigilância Sanitária. Como os Conselheiros de Saúde pensam e percebem o mundo da Vigilância Sanitária? Quais são suas experiências com esse mundo?

\section{Métodos}

A pesquisa aqui apresentada refere-se ao pensamento e ao conhecimento dos Conselheiros de Saúde de Belo Horizonte sobre o tema Vigilância Sanitária e, dessa maneira, a pesquisa qualitativa de representação social se apresenta como método de escolha mais apropriado. Segundo Minayo $^{11}$, esse tipo de abordagem metodológica atua considerando a compreensão, a inteligibilidade dos fenômenos sociais e o significado e a intencionalidade que lhe atribuem os atores.

Nesse sentido, foram entrevistados 35 dos 36 membros efetivos do Conselho Municipal de Saúde de Belo Horizonte (CMSBH), no período de maio a agosto de 2009, por meio da técnica de entrevista baseada em roteiro semiestruturado. Complementarmente, recorreu-se à técnica de pesquisa documental, com análise dos Planos de Ação da Vigilância Sanitária de Belo Horizonte de 2008 e 2009. Este estudo foi previamente aprovado pelo Comitê de Ética em Pesquisa da Secretaria Municipal de Saúde de Belo Horizonte.

Os dados obtidos foram analisados pela técnica do Discurso do Sujeito Coletivo (DSC) ${ }^{12}$ que, a partir de uma estratégia discursiva, busca tornar mais clara uma dada representação social. Foram identificadas as expressões-chave, que são trechos selecionados do material verbal de cada depoimento que melhor descrevem seu conteúdo. As ideias centrais, que são formulações sintéticas que descrevem o(s) sentido(s) presente(s) no material e também nos conjuntos de respostas de diferentes indivíduos, que possuam sentido semelhante ou complementar e, então, construídos os DSC.

\section{Resultados e discussão}

Com a finalidade de conhecer e analisar as experiências dos Conselheiros de Saúde de Belo Horizonte com a vigilância sanitária foi proposta a seguinte questão aberta: Fale um pouco pra gente de sua experiência com a vigilância sanitária, enquanto conselheiro ou no seu dia a dia (Quadro 1).

\section{A - Curso de capacitação em vigilância sanitária}

DSC

Bom!... Enquanto conselheiro, a gente teve um contato com a vigilância no ano passado, porque houve um curso de capacitação pra conselheiros... pra inclusive explicar qual é o papel da vigilância pra gente. Nós participamos e foi extremamente positivo a troca de experiências, até pra gente conhecer um pouco o outro lado, porque a gente sempre conhece o nosso lado em relação à atuação da vigilância. Então, é uma forma da gente tá... percebendo a vigilância... esse processo todo, esse sistema todo. Foi muito legal!

Quadro 1. Síntese das ideias centrais

\begin{tabular}{|l|l|}
\hline A & Curso de capacitação em vigilância sanitária \\
\hline B & $\begin{array}{l}\text { O Conselho Municipal de Saúde e a vigilância } \\
\text { sanitária }\end{array}$ \\
\hline C & Campo de atuação da vigilância sanitária \\
\hline D & $\begin{array}{l}\text { Dificuldades na realização do trabalho de } \\
\text { vigilância sanitária }\end{array}$ \\
\hline E & $\begin{array}{l}\text { Vigilância sanitária e o princípio da } \\
\text { universalidade }\end{array}$ \\
\hline F & Vigilância sanitária e a situação de saúde \\
\hline G & Educação em saúde \\
\hline H & Vigilância em saúde \\
\hline I & $\begin{array}{l}\text { Vigilância sanitária e o atendimento a } \\
\text { denúncias }\end{array}$ \\
\hline J & Vigilância sanitária de alimentos \\
\hline K & Vigilância sanitária de serviços de saúde \\
\hline L & Vigilância sanitária de produtos \\
\hline
\end{tabular}




\section{B - O Conselho Municipal de Saúde e a vigilância sanitária}

DSC

Bom!... Dentro da área de conselheiro a gente fiscaliza comércio, estabelecimentos hospitalares e postos de saúde. Como vigilância sanitária e como conselheiro. Então, a gente observa o que é prejudicial pra família, pro povo, pra população e, a partir do momento que se torna prejudicial, a gente entra na fiscalização.

Então, a experiência no conselho [com a vigilância], só em reunião, a gerente da vigilância sanitária colocando as ações e as limitações. Às vezes também, as discussões vêm a plenário, mas só em pontos especificos e não de esclarecimentos mais amplos, o que eu acho até que seria mais importante.

Porém, a vigilância sanitária, esse ator social... ele não pode se eximir de um controle social. Ele tem que passar pelo crivo do Conselho Municipal de Saúde, para que a gente possa tar olhando e contribuindo para o aprimoramento desse tipo de trabalho, e até contribuindo para que recursos possam ser alocados para a vigilância sanitária.

Os discursos dos sujeitos coletivos dos grupamentos A e B apresentam experiências que envolvem tanto o Conselho de Saúde quanto a vigilância sanitária. Todavia, foram agrupados separadamente em função da prevalência, no grupo A, da experiência dos conselheiros com o curso de capacitação "Vigilância Sanitária e o Conselho Municipal de Saúde", promovido pela Vigilância Sanitária de Belo Horizonte, no final de 2008.

A realização do curso obedece à programação do Plano Local de Ação, de 2008. O Plano de Ação retrata a Programação Anual de Vigilância Sanitária, ou seja, é uma ferramenta de planejamento onde estão descritas as atividades a serem desenvolvidas, as metas e resultados esperados e seus meios de verificação, os recursos financeiros implicados, os responsáveis e as parcerias necessárias para a execução dessas ações ${ }^{7}$. Dessa forma, o Plano Local classifica como problema "O desconhecimento dos conselheiros de saúde sobre a vigilância sanitária e suas atribuições"; como indicador do problema das "Demandas inadequadas"; como risco sanitário à "Atuação política do controle social sem o necessário conhecimento técnico em vigilância sanitária"; e como operação/ ação da "Participação da vigilância sanitária no processo de formação de conselheiros de saúde"13.

Vale ressaltar que a Resolução do $\mathrm{CMSBH}^{14}$ que aprovou o Plano Local de Ação para 2008, o faz com a seguinte a recomendação: "Que os Conselheiros Municipais de Saúde sejam capa- citados como consta no plano". A I Conferência Nacional de Vigilância Sanitária (Conavisa) ${ }^{15}$ já havia alertado, por meio da recomendação de $n^{\circ}$ 194, para a necessidade de se promover, através de diversas estratégias e instrumentos, ações de informação e comunicação, visando a construção da consciência sanitária. Ao participarem do curso de capacitação de vigilância sanitária os conselheiros tiveram a oportunidade de construírem o saber prático, combinando essas informações com as informações prévias, suas experiências e seus valores. Assim, se daria a construção das representações sociais. Dessa forma, aquele objeto misterioso, após ser devidamente destrinchado e recomposto, torna-se algo efetivamente palpável, passando a parecer-lhes natural ${ }^{16}$.

Todavia, é importante observar que não existe uma preocupação por parte da Vigilância Sanitária de Belo Horizonte em formar conselheiros com conhecimentos em vigilância sanitária, para que possam participar politicamente da elaboração do Plano Local de Ação. Nesse sentido, Oliveira ${ }^{17}$ recomendou à Anvisa, visando qualificar o processo de planejamento das ações e serviços de vigilância sanitária, e, consequentemente, a gestão em vigilância sanitária, estimular a participação de Conselheiros de Saúde na elaboração do plano/programação.

E dessa forma, atender-se-ia à demanda do sujeito coletivo do grupamento $\mathrm{B}$, que exige que o planejamento da vigilância sanitária passe pelo crivo do Conselho Municipal, porque ela não pode se eximir de um controle social e, ao passar pelo conselho, este poderia contribuir para que recursos possam ser alocados para a vigilância sanitária. Também é citado nesse discurso que a vigilância sanitária está presente no conselho só em reuniões: a gerente da vigilância sanitária colocando as ações e as limitações.

Essas reuniões a que se refere o sujeito coletivo tratam exatamente da apresentação do Plano Local de Ação da Vigilância Sanitária para os conselheiros, nas câmaras técnicas e no plenário do conselho, tendo como finalidade sua aprovação, visando legitimar o financiamento e o repasse de recursos. Nesse contexto, esses conselheiros não reconhecem na apresentação do Plano Local de Ação, os mecanismos que seriam próprios da participação e do controle social, mas apenas a formalização de uma exigência legal ${ }^{17}$.

Outra interessante observação feita por esse sujeito coletivo: a gente fiscaliza comércio, estabelecimentos hospitalares e postos de saúde, como vigilância sanitária e como conselheiro. Os conselheiros parecem confundir sua atividade de 
"fiscalização", feita principalmente nos serviços de saúde, com a atividade propriamente dita de vigilância sanitária. Essa confusão poderia ser prontamente resolvida, se fosse cumprida a recomendação de $n^{\circ} 228$ da I Conavisa ${ }^{15}$, que propõe o estabelecimento de uma agenda conjunta entre vigilância sanitária e Conselho de Saúde, para a fiscalização de estabelecimentos públicos e conveniados ao Sistema Único de Saúde (SUS).

\section{C- Campo de atuação da vigilância sanitária}

DSC

Eu acho importantíssimo o trabalho da vigilância! Qual medicamento pode ser usado, até quando pode ser usado, como deve ser passada a informação através da bula. A vigilância sanitária tem um campo de atuação muito grande, tem que cuidar da questão dos consultórios [...] dos ambulatórios, dos bancos de sangue, do controle [da qualidade] das vacinas. Uma coisa que chama muito a atenção hoje, por exemplo, são os salões de beleza, do ponto de vista da assepsia [...].

Então, a vigilância sanitária pode tanto interditar um açougue que vende carne estragada quanto um hospital, que não cumpre as regras minimas de higiene. Dessa forma, o trabalho da vigilância sanitária é muito amplo, ele se confunde com a própria experiência de vida das pessoas.

\section{D- Dificuldades na realização do trabalho de vigilância sanitária}

\section{DSC}

Eu sentia muita dificuldade do fiscal ir ao hospital. Eu pedia... diziam não, não tem jeito porque temos um contingente pequeno de vigilantes sanitários. E quando o fiscal chegava era muito mais pra chamar a atenção do hospital [...] pra multar. Então, a minha experiência é com a falta de preparo do profissional da vigilância sanitária em estar atuando, muitas vezes, a falta de sensibilidade do profissional.

A gente sabe que é pra seguir a lei, mas muitas vezes detalhes miúdos poderiam ser relevados [...]. A questão sanitária ultrapassa até o texto da lei... às vezes é muito mais bom senso! A gente senta, conversa tecnicamente, mas ainda tem uma resistência muito grande da vigilância.

Por isso, a obrigação do controle social é acompanhar de perto o trabalho deles, porque tem muita coisa pra melhorar na vigilância sanitária, muita coisa que ainda deixa a desejar!

\section{E- Vigilância sanitária e o princípio da universalidade}

\section{DSC}

Eu sou de uma cidade muito pequena onde a vigilância sanitária [...] era ligada à prefeitura e então, a vigilância sanitária só autuava quem era contra o prefeito. Dessa forma, acho importante essa mudança que o SUS traz hoje, essa noção de vigilância sanitária ligada à saúde.

Não sei até que ponto também, a vigilância sanitária poderia estar atuando junto com o direito do consumidor. Para fortalecer as instâncias, para que haja uma maior qualidade de vida, que é o que nós esperamos que seja conferido para todas as pessoas! A vigilância sanitária tem um papel fundamental nesse ponto.

Muitas vezes, a gente fala, e a gente escuta muito falar!... Ahh!... Eu não uso o SUS!... No aspecto assistencial, mas indiretamente usa! A vigilância sanitária traz o caráter universal do Sistema Único de Saúde. Então, é uma área que de fato a gente tem, enquanto país, um avanço muito claro em benefício da população.

O sujeito coletivo do grupamento C observa que o trabalho da vigilância sanitária é muito amplo, estando presente nas diversas situações cotidianas, devido a diversidade de seus objetos ${ }^{18}$, e, dessa maneira, se confunde com a própria experiência de vida das pessoas.

Lucchese $^{16}$ afirma que a atividade de vigilância sanitária não somente faz parte das competências do SUS, como tem caráter prioritário, por sua natureza essencialmente preventiva. Não é à toa que o sujeito coletivo do grupamento E constata o caráter universal que a vigilância sanitária traz agregado a suas ações. Observa também, que a manutenção desse caráter universal se dá em função do pertencimento da vigilância sanitária ao Sistema Único de Saúde (SUS).

Esse sujeito coletivo ainda questiona até que ponto a vigilância sanitária poderia atuar junto com o direito do consumidor. Nesse sentido, Dalla$\mathrm{ri}^{19}$ comenta que os órgãos de vigilância sanitária compõem o sistema de defesa do consumidor, devendo então aprender a trabalhar também com essa ótica. Por sua vez, os órgãos de defesa do consumidor na área da saúde dependem da vigilância sanitária para atuar com o poder de polícia. Dessa forma, é conveniente aproximar os agentes desses dois sistemas para que se possa proceder a divisão de tarefas, observando a realidade local.

Porém, essa aproximação dos agentes esbarra na constatação, verificada através de um discurso coletivo prevalente, acerca do número insu- 
ficiente de trabalhadores na Vigilância Sanitária de Belo Horizonte. Nesse sentido, o discurso do sujeito coletivo do grupamento D fala de experiências que retratam as dificuldades na realização do trabalho de vigilância sanitária. Além do já citado contingente pequeno de trabalhadores, esse sujeito coletivo aponta também, para a falta de preparo do profissional da vigilância sanitária em estar atuando.

Costa $^{20}$ esclarece que o exercício profissional de vigilância sanitária implica em informação e conhecimento científico atualizado, requer saberes específicos de vários ramos do conhecimento e saberes específicos, não incluídos nos cursos de graduação em saúde ou nas outras profissões que também atuam na vigilância sanitária. Além disso, existe a demanda por um conjunto de práticas estruturadas, baseadas em conhecimento técnico-científico, e em valores que influem nos processos de decisão e que, por vezes, contrariam interesses, provocando os mais diversos tipos de pressão ${ }^{20}$.

Para tanto, a capacitação dos profissionais de vigilância sanitária exige a adoção de estratégias de ensino-aprendizagem complexas, ou seja, o uso de formas e procedimentos de ensino que permitam uma maior reflexão e a participação dos profissionais, tendo como base suas experiências concretas ${ }^{21}$.

Nesse contexto, observamos no Plano Local de Ação da Vigilância Sanitária $2008^{13}$ e $2009^{22}$ o problema "Conhecimentos insuficientes de vários campos dos saberes de vigilância sanitária"; o indicador do problema "Dificuldade de atuação na rotina fiscal"; o risco sanitário "Qualidade insatisfatória nas ações e serviços de vigilância sanitária"; e a operação/ação "Capacitação técnica dos fiscais sanitários" em: endoscopia, CTI/UTI, lavanderia hospitalar, bloco cirúrgico, reprocessamento de artigos, laboratório de citopatologia, quimioterapia, salão de beleza, radiodiagnóstico médico e odontológico, açougue, farmácia hospitalar, assistência hemoterápica, radioterapia e medicina nuclear, laboratório de análises clínicas e anatomia patológica, hemodiálise, controle de infecção, hemodinâmica, doenças transmitidas por alimentos e investigação de surto, entre outros.

Cabe ressaltar que essa operação/ação de capacitação técnica é realizada pelos próprios fiscais para seus pares. O fiscal "escolhe" o tema pelo qual tem maior afinidade, estuda as legislações vigentes, artigos relacionados, informes da Anvisa e, é claro, o saber prático, e multiplica esse conhecimento para os demais colegas fiscais. Assim, o que se observa é um esforço hercúleo por parte dos profissionais da vigilância sanitária em busca de uma "capacitação técnica". Se, por um lado, estimular esses profissionais a refletirem acerca da realidade cotidiana é extremamente positivo, por outro, atribuir a esses mesmos trabalhadores a responsabilidade de elaborarem uma "pedagogia" que lhes proporcione um conhecimento técnico, científico e ético é de uma perversidade extrema.

Não obstante as dificuldades citadas, ainda existe a necessidade urgente de atualização técnico-científica, para acompanhar as mudanças tecnológicas que se expressam na rápida dinâmica do setor produtivo ${ }^{20}$ e que, muitas vezes, ainda não foram contempladas com a respectiva produção normativa. O discurso do sujeito coletivo do grupamento $\mathrm{D}$ também percebe essa dificuldade, ao afirmar que a questão sanitária ultrapassa o texto da lei, sendo às vezes, muito mais bom senso. Novamente, $\operatorname{Costa}^{20}$ esclarece que as diversas situações reais que se apresentam para as decisões da vigilância sanitária, nem sempre estão enquadradas na lei, implicando em capacidade de julgamento e poder discricionário, com senso ético e de responsabilidade pública.

\section{F- Vigilância sanitária e a situação de saúde}

\section{DSC}

Vigilância sanitária é no sentido de vigiar, de participar [...]. A gente tenta chamar a atenção, acionando os órgãos de defesa, pra coisas que a gente vê por aí que afetam a saúde do cidadão. Porque no meu entender, nós vivemos o dia a dia dentro de situações desagradáveis. Por exemplo, vivemos aí esta importação da situação que está ocorrendo no mundo!... Então, nós temos que estar sempre atentos à higiene.

\section{G- Educação em saúde}

DSC

No dia a dia, tive uma experiência [...] na área da saúde ambiental. A gente participava de um projeto no município de Nova Lima, com jovens escoteiros. A gente falava de agente químico, em relação ao consumo de água, que tipo de prejuízo aquilo poderia trazer para a comunidade.

Outra experiência foi em consertar esgotos e tirar porcos de dentro de vilas com a vigilância sanitária. Tivemos uma conscientização. O povo aceitou legal! O agente da vigilância sanitária entrou e conversou... Foi interessante porque o pessoal entendeu que o fiscal não tá ali pra multar, ele tá ali pra orientar! E as pessoas pra serem orientadas... 
visam muito o conhecimento. Porque as pessoas precisam de explicação, porque não conhecem... acham que o fiscal vai lá pra multar.

Hoje, a gente tem uma atividade que eu acho fundamental!... Não são todas as pessoas que têm essa visão, da vigilância sanitária, apesar que eu acho que tá mudando! É que a gente faz cursos de boas práticas de manipulação. Vai ter um evento, vai ter uma feira todo sábado!... O que é que a gente faz? A gente reune, antes do evento acontecer, com os profissionais que vão estar nesse evento, nesse comércio, pra preventivamente... orientá-los. [...]. Com isso, a gente tem obtido uma melhoria do serviço prestado à população, além de evitar o risco de uma intoxicação alimentar. Eu acho que é uma contribuição muito importante da vigilância sanitária, como fator preventivo e educacional.

\section{H- Vigilância em saúde}

\section{DSC}

De fato, a atividade da vigilância vem progressivamente sendo refinada, profissionalizada, qualificada. A criação da Anvisa teve um papel fundamental nesse processo, mas tá ficando uma lacuna!... E é polêmico isso! Precisamos aprimorar com a apropriação sistêmica do ponto de vista da política de saúde, da estratégia da política de saúde que o sistema de vigilância tem a oportunidade de gerar. Olhando o debate na tripartite, olhando o debate na CIB, não é que ela esteja à parte... da construção da política pública de saúde numa perspectiva de conter agravos, de promover saúde, de gerenciar o risco sanitário [...]. Eu acho que a política pública de saúde ainda se apropria pouco daquilo que a vigilância sanitária... e eu acho que o movimento está correto de evolução de vigilância sanitária para vigilância em saúde, tá corretíssimo, o movimento institucional também é nesse sentido. São dois movimentos institucionais muito concretos... um é Agência e outro é a Secretaria de Vigilância. Agora, esse casamento... essa interface, é natural que seja assim, nós todos ainda estamos aprendendo, todos... profissionais, gestores [...]. Eu acho que ainda temos muito que aprimorar a política numa perspectiva de apropriar sistematicamente os benefícios e as ferramentas que a vigilância pode propiciar.

O sujeito coletivo do grupamento $\mathrm{F}$ faz referência às situações desagradáveis que vivemos no dia-a-dia, e exemplifica com a importação da situação que está ocorrendo no mundo. Dessa forma, o sujeito coletivo se refere à Influenza A $\left(\mathrm{H}_{1} \mathrm{~N}_{1}\right)$, chamando a atenção para o processo de globalização dos riscos, o que exige, segundo Dallari ${ }^{19}$, a implementação de um complexo sistema de vigilância sanitária nacional e internacional. A atual epidemia do Ebola, no continente Africano, demonstra que as emergências internacionais em Saúde Pública serão cada vez mais frequentes.

O sujeito coletivo do grupamento $\mathrm{G}$ fala sobre experiências educativas relacionadas à atividade de vigilância sanitária, incluindo uma atividade educativa na área de vigilância ambiental. Entre as experiências relatadas está uma atuação da vigilância sanitária dentro de vilas, verificando esgoto e retirando porcos.

Tivemos uma conscientização. O povo aceitou legal! O agente da vigilância sanitária entrou e conversou.

Segundo Lucchese $\mathrm{L}^{16}$, a vigilância sanitária constitui espaço privilegiado para a comunicação e promoção da saúde, por lidar com produtos e serviços presentes no cotidiano dos indivíduos e pela necessária interação com a sociedade, função que é exigida para o adequado gerenciamento do risco sanitário. Ainda segundo o autor, a ação educativa no âmbito da vigilância sanitária pode ser utilizada tanto no que se refere ao entendimento do risco à saúde envolvido nos atos e nas situações cotidianas, quanto no que se relaciona aos direitos de cidadania.

Por sua vez, o sujeito coletivo do grupamento $\mathrm{H}$, refletindo sobre as discussões que ocorrem na Comissão Intergestores Tripartite (CIT) e na Comissão Intergestores Bipartite (CIB), apresenta um discurso político para a evolução de vigilância sanitária para vigilância em saúde. De acordo com esse sujeito coletivo, a criação da Anvisa permitiu que a atividade de vigilância fosse profissionalizada, refinada e qualificada, possibilitando também, avanços nas formas de gestão da vigilância ${ }^{18}$. Entretanto, esse avanço profissional e organizacional gerado pela instituição da agência, não foi capaz de resolver o que Costa ${ }^{20}$ classifica como a persistência de certo descolamento das demais ações de saúde. Dessa forma, ainda não ocorreria uma apropriação sistêmica, do ponto de vista da política de saúde, das estratégias que o sistema de vigilância tem a oportunidade de gerar.

A solução para essas dificuldades se daria através da evolução da vigilância sanitária para vigilância em saúde. Cabe observar que, tradicionalmente, vigilância sanitária e vigilância epidemiológica, apesar de integrarem o campo da proteção e prevenção, foram tratadas em separado, nas políticas de saúde brasileiras ${ }^{23}$, o que poderia justificar as dificuldades nesse casamento entre a Anvisa e a Secretaria de Vigilância em Saúde. Essa união se concretizaria através da execução 
de ações da vigilância em saúde, na perspectiva de potencializar a execução das ações das vigilâncias: sanitária, epidemiológica, ambiental e de saúde do trabalhador e, assim, teríamos a possibilidade de aprimorar a politica numa perspectiva de apropriar sistematicamente os benefícios e as ferramentas que a vigilância pode propiciar.

\section{I- Vigilância sanitária e o atendimento a denúncias}

DSC

Tem também a atenção que eles dão às denúncias e eu acho importantíssimo! Quando a gente faz uma denúncia pra vigilância sanitária, a gente vê imediatamente que o lugar está sendo verificado... se é aquilo mesmo que foi informado.

Um exemplo foi um supermercado próximo da minha casa que estava vendendo alimentos vencidos! Aí nós cobramos da vigilância sanitária a investigação... o que estava acontecendo com esse supermercado.

\section{J- Vigilância sanitária de alimentos}

DSC

Acordo e vou tomar meu café, lá estão todos os alimentos inspecionados. Então, no dia a dia, podemos dizer... estou consumindo o produto, ou melhor, o serviço da vigilância sanitária.

Ela está presente também, na minha regional. Está presente em todos os eventos, está lá fiscalizando, olhando pra ver se tá tudo bem. Sempre que a gente chama... a vigilância sanitária nos atende. Precisamos dela pra olhar a alimentação das Unidades de Urgência, eles foram vigilantes, pegaram amostras e fizeram os exames. Forneceram um laudo para a empresa e ela foi credenciada.

Eu venho de uma empresa que atua com alimentação, na área hospitalar, e o que nos sabemos é que quando a vigilância vai à empresa,o profissional da vigilância registra sua avaliação. A empresa tem que ter controle microbiológico da alimentação e controle de saúde dos trabalhadores que manipulam os alimentos. Tem que fornecer treinamento de higienização e de manipulação dos alimentos. Então, a vigilância é importante porque aquele alimento está sendo produzido dentro dos padrões estabelecidos e chegando lá na frente com qualidade.

\section{K- Vigilância sanitária de serviços de saúde}

DSC

A gente tem uma experiência com o sindicato de odontologia e com a vigilância sanitária... e realmente, a gente teve muitos ganhos... porque a vigilância sanitária foi e apontou vários erros que estavam acontecendo, de fatores que poderiam levar ao adoecimento e à própria transmissão de infecções. A gente teve ganho com a vigilância... não foi uma coisa punitiva... foi uma coisa de orientação! Eu vejo a vigilância sanitária muito com esse papel de orientar.

Outro exemplo, os espaços nos hospitais, de um leito para outro... pelo menos nos CTI... muitas vezes, em alguns CTI colocam acima do número normal de pacientes!... Diminuem o espaço... isso aí é infecção hospitalar que pode acontecer!

Dessa forma, as coisas têm que estar nos seus lugares, porque isso significa qualidade na assistência! Se você tem uma lixeira de forma inadequada... um 'descarpak' fora do lugar ou jogando seringa, né!... Você tem que adequar!... Não é porque o fiscal tá indo, é porque aquilo é bom para o usuário e para os profissionais de saúde. Eu acho que nós temos essa consciência. O papel do fiscal tem que ser mais educativo no primeiro momento, agora no final, o papel do fiscal é multar sim, porque enquanto cidadã, se eu for ao hospital e tiver coisas fora da norma... com certeza vou ser prejudicada! Então, eu penso assim... eu gostaria de dar pra aquele usuário do meu serviço o que eu gostaria de receber.

\section{L- Vigilância sanitária de produtos}

DSC

A minha experiência é de estar consumindo produtos que sejam inspecionados, que sejam autorizados e acompanhados pela vigilância sanitária. Dessa maneira, são questões ligadas a vigilância sanitária que impactam no meu trabalho. Por exemplo, um laboratório [Indústria Farmacêutica] de Sabará com um anestésico infectado. Eu mesmo já tinha trabalhado com anestésicos desse laboratório, um negócio meio complicado você estar num ambiente em que esse risco exista... Um laboratório ter contaminação de produto!

No grupamento I, o sujeito coletivo relata experiências relativas às denúncias feitas à vigilância sanitária, e demonstra total satisfação com a atenção que eles dão as denúncias. Para tanto, o Plano Local de $\mathrm{Ação}^{22}$ estabelece como problema os "Estabelecimentos, serviços e produtos não conformes encaminhados pela população"; como 
indicador do problema as "Denúncias recebidas"; e como risco sanitário o "Prejuízo à população". Dessa maneira, a vigilância sanitária tem como meta o atendimento de $100 \%$ das reclamações e denúncias registradas, atendendo prontamente às necessidades sentidas pela população.

Os sujeitos coletivos dos grupamentos J, $\mathrm{Ke}$ L se manifestam através de discursos que trazem os tradicionais objetos de ação de vigilância sanitária, quais sejam: alimentos, serviços e produtos.

O discurso referente aos alimentos destaca situações em que a vigilância sanitária é responsável pela inspeção e fiscalização de alimentos industrializados e in natura. Destaca também a importância da atuação da vigilância sanitária tanto no setor público, nas unidades de emergência do SUS, quanto no setor privado, junto a empresas de alimentação hospitalar, e como a atuação da vigilância sanitária nesses setores agrega qualidade e segurança aos alimentos produzidos.

Os serviços são caracterizados, no discurso do sujeito coletivo do grupamento K, como serviços de saúde. As experiências relatadas dizem respeito à ação da vigilância sanitária como instrumento de qualidade diretamente relacionado ao controle de infecções e avaliação de riscos à saúde, beneficiando não só os usuários de serviços hospitalares, mas também, os usuários de serviços odontológicos.

Outra observação interessante está relacionada à conduta do profissional de vigilância sanitária. No exercício da atividade fiscalizadora, parece ser unanimidade que $o$ fiscal, no primeiro momento, tenha um papel de orientação, ou seja, que adote uma postura mais educativa. Entretanto, após essa orientação inicial, se for comprovado a persistência ao desrespeito à norma, então, o fiscal é incitado a multar sim, porque enquanto cidadã, se eu for ao hospital e tiver coisas fora da norma, com certeza vou ser prejudicada.

Por sua vez, o sujeito coletivo do grupamento $L$ apresenta uma experiência negativa em relação à inspeção e autorização de produtos, sob responsabilidade da vigilância sanitária, pois esta não consegue impedir a distribuição e venda de medicamentos alterados por contaminação bacteriana, resultando em óbitos de pacientes.

\section{Considerações finais}

A prática de encontros pontuais visando à aprovação do Plano Local de Ação e a realização de um único curso de capacitação para conselheiros comprova o distanciamento existente entre a Vigilância Sanitária de Belo Horizonte e o Conselho Municipal de Saúde. Todavia, esse distanciamento é compensado pela riqueza das experiências "vividas" pelos conselheiros. Essas experiências foram ressignificadas em saber prático, influenciando diretamente o pensamento e o conhecimento desses sujeitos sobre o tema.

Dessa forma, os Conselheiros de Saúde reconhecem o trabalho da vigilância sanitária nas diversas situações cotidianas, confundindo-o com a própria experiência de vida das pessoas. Percebem o caráter universal que a vigilância sanitária traz agregado a suas ações, verificando que a manutenção desse caráter universal se dá em função do pertencimento da vigilância sanitária ao Sistema Único de Saúde. A natureza preventiva da vigilância sanitária, bem como sua tarefa de proteger e promover a saúde dos cidadãos, também é apreendida pelos conselheiros.

Por fim, a comprovação da apropriação social sobre a importância da vigilância sanitária como ação de saúde ${ }^{20}$ a qualifica como eficaz modelo de atenção à saúde, intervindo sobre os fatores determinantes e condicionantes do processo saúde doença, ao mesmo tempo em que promove ações educativas que contribuem para elevar a consciência sanitária na percepção do risco sanitário e na compreensão do funcionamento do Sistema Nacional de Vigilância Sanitária.

\section{Colaboradores}

AMC Oliveira trabalhou na concepção, coleta e análise de dados e redação do artigo; SG Dallari foi a orientadora, colaborando também na revisão crítica e aprovação da versão a ser publicada. 


\section{Referências}

1. Brasil. Constituição da República Federativa do Brasil de 1988. Diário Oficial da União 1988; 5 out.

2. Dallari DA. Ética sanitária. In: Brasil. Ministério da Saúde (MS). Direito sanitário e saúde pública. Brasília: MS; 2003. v. 1. p. 65-86.

3. Costa EA, Bonfim Jr A. O movimento de construção do Sistema de Vigilância Sanitária no país. Divulg Saude Debate 2001; (25):4-5.

4. Lucchese G. Globalização e regulação sanitária: os rumos da vigilância sanitária no Brasil [tese]. Rio de Janeiro: Fiocruz; 2001.

5. Dallari SG. O direito sanitário como campo fundamental para a vigilância sanitária. In: Faculdade de Saúde Pública. Vigilância sanitária: textos e contextos. São Paulo: USP; 2004. p. 7-23.

6. Brasil. Lei no 8.080 , de 19 de setembro de 1990. Dispõe sobre as condições para a promoção, proteção e recuperação da saúde, a organização e o funcionamento dos serviços correspondentes e dá outras providências. Diário Oficial da União 1990; 20 set.

7. Agência Nacional de Vigilância Sanitária (Anvisa). Plano diretor de vigilância sanitária. Brasília: Anvisa; 2007.

8. Moscovici S. Representações sociais: investigações em psicologia social. Petrópolis: Vozes; 2003.

9. Arruda A. Teoria das representações sociais e teorias de gênero. Cad Pesquisa 2002; (117):127-147.

10. Spink MJP. O conceito de representação social na abordagem psicossocial. Cad Saude Publica 1993; 9(3):300308.

11. Minayo MCS. O desafio do conhecimento: pesquisa qualitativa em saúde. São Paulo, Rio de Janeiro: Hucitec, Abrasco; 2000.

12. Lefèvre F, Lefèvre AMC. O discurso do sujeito coletivo: um novo enfoque em pesquisa qualitativa: desdobramentos. Caxias do Sul: EDUCS; 2003.

13. Secretaria Municipal de Saúde de Belo Horizonte. Gerência de vigilância em saúde e informação. Plano local de ação da vigilância sanitária de Belo Horizonte. Belo Horizonte: SMSA; 2008.

14. Conselho Municipal de Saúde de Belo Horizonte. Resolução 222 - Aprova o Plano Local de Vigilância Sanitária para 2008. Belo Horizonte: CMSBH; 2008.

15. Conferência Nacional de Vigilância Sanitária. I Conferência Nacional de Vigilância Sanitária: Relatório Final. Brasília: Agência Nacional de Vigilância Sanitária; 2001.
16. Lucchese G. A vigilância sanitária no Sistema Único de Saúde. In: De Seta MH, Pepe VLE, Oliveira G, organizadoras. Gestão e vigilância sanitária: modos atuais do pensar e fazer. Rio de Janeiro: Fiocruz; 2006. p. 33-47.

17. Oliveira AMC, Dallari SG. Participação social no planejamento das ações e serviços de vigilância sanitária: uma análise crítica. Vigilância Sanitária em Debate: Sociedade, Ciência \& Tecnologia 2014; 2:9-16.

18. O'Dwyer G, Reis DCS, Silva LLG. Integralidade, uma diretriz do SUS para a vigilância sanitária. Cien Saude Colet 2010; 15(Supl. 3):3351-3360.

19. Dallari SG. Vigilância Sanitária: responsabilidade pública na proteção e promoção da saúde. In: Costa EA, organizadora. Vigilância sanitária: desvendando o enigma. Salvador: Edufba; 2008. p. 45-52.

20. Costa EA. O trabalhador de vigilância sanitária e a construção de uma nova vigilância: fiscal ou profissional de saúde? In: Costa EA, organizadora. Vigilância sanitária: desvendando o enigma. Salvador: Edufba; 2008. p. 77-90.

21. Souza AMAF, Marques SB, Vignola SR. Formação de recursos humanos para o Sistema Nacional de Vigilância Sanitária: uma breve discussão sobre questões pedagógicas. In: Faculdade de Saúde Pública. Vigilância Sanitária: textos e contextos. São Paulo: USP; 2004. p. 35-38.

22. Secretaria Municipal de Saúde de Belo Horizonte. Gerência de vigilância em saúde e informação. Plano local de ação da vigilância sanitária de Belo Horizonte. Belo Horizonte: SMSA; 2009.

23. Lucchese G. Descentralização e modelo sistêmico: o caso da vigilância sanitária. Cien Saude Colet 2010; 15(Supl. 3):3020-3026.

Artigo apresentado em 03/09/2014

Aprovado em 26/11/2014

Versão final apresentada em 28/11/2014 